\title{
Peripheral nerve involvement in sarcoidosis: an electrodiagnostic study
}

\author{
YASOMA B CHALLENOR, CHARLES P FELTON, JOHN CM BRUST \\ From the Department of Neurology and Medicine, Harlem Hospital Center, Columbia University College of \\ Physicians and Surgeons, New York, New York, USA
}

\begin{abstract}
SUMMARY The frequency of peripheral nerve involvement in sarcoidosis is uncertain. To determine how often peripheral nerves are affected in the absence of symptoms, electromyography was performed on 29 sarcoid patients and 29 age-matched controls. Nineteen sarcoid patients, compared to two controls, had abnormally low sensory amplitudes in one or more nerves, and the mean sensory amplitudes for median, ulnar, and sural nerves were lower in the patient than in the controls. Subclinical mononeuropathy multiplex appears to be common in sarcoidosis.
\end{abstract}

The incidence of neurological disorder in sarcoidosis is about $4 \%,,^{12}$ and intermittent cranial nerve palsies are the most frequent manifestations. Symptomatic symmetrical peripheral neuropathy is uncommon, and occasionally acute forms must be distinguished from Guillain-Barré syndrome. ${ }^{34}$ Subacute peripheral neuropathy has also been reported. ${ }^{4}$ Of all types of sarcoid neuropathy, mononeuropathy multiplex (particularly cranial neuropathy) is the commonest. ${ }^{3}$ We used electrical studies to determine whether there is evidence of subclinical peripheral nerve involvement in neurologically asymptomatic patients with sarcoidosis.

\section{Method}

Patients being followed by the medical service for proven sarcoidosis were referred for nerve conduction studies and electromyography (EMG). Of the 35 patients who reported for this examination, six were eliminated from the study: two had lumbosacral radiculopathy, two had symptomatic mononeuropathy multiplex, one was alcoholic, and one was insufficiently studied. The remaining 29 patients were well-nourished, and none had clinical or laboratory evidence of diseases that might affect peripheral nerve function, such as diabetes, chronic renal failure, or alcoholism. Neurologic examination was normal in all cases except as noted (table 1). These 29 patients ranged in age from 16

Address for reprint requests: Dr Challenor, Harlem Hospital Center, 506 Lenox Avenue, New York, New York 10037, USA.

Received 20 August 1981 and in revised form 30 April 1984. Accepted 5 May 1984 to 55 years (mean 36 years). Twenty-two were women (ages 16 to 55 years, mean 36) and seven men (ages 24 to 46 , mean 35). There was histological confirmation of sarcoid in 28 patients, and the other one had incontrovertible clinical evidence of the disease (table 1). Controls comprised patients matched for age and sex, and similarly free of diseases or medications that might affect peripheral nerve function.

Standard Teca TE-3 or TE-4 units were used for nerve conduction studies and EMG. Rectangular pulses of up to $200 \mathrm{~V}$ and up to a maximum of $1.0 \mathrm{~ms}$ were delivered percutaneously to two superficial points on each nerve tested, with a surface recording electrode over the appropriate distal muscle innervated by the nerve being studied, and a reference electrode over an adjacent tendinous insertion. Compound evoked muscle responses and sensory potentials were recorded on a fiberoptic recorder for accurate measurement and calculation. Sensory potentials were evoked antidromically with percutaneous stimulation using digital ring recording electrodes for the upper limb studies. The sural nerve was stimulated orthodromically with a fixed-mount recording electrode over the nerve. Respective stimulation and recording points for the sensory studies were: median nerve at the wrist between the flexor carpi radialis and palmaris longus tendons, recording from ring electrodes on the index finger; ulnar nerve at the wrist lateral to the flexor carpi ulnaris tendon, recording from ring electrodes on the fifth digit; and sural nerve behind the lateral malleolus recording $12 \mathrm{~cm}$ proximally, just lateral to the midline of the calf.

Ambient room temperature was maintained over $23^{\circ} \mathrm{C}$, and the limbs were kept warm during examination. (Skin temperatures were above $29^{\circ} \mathrm{C}$ for the digits and proximal extremities). For sensory latency studies before 1977 , averaging techniques were not used, and potentials less than 5 microvolts $(\mu V)$ may have been missed. Subsequently, averaging equipment was available. Techniques did not differ between patients and controls, in seven of whom only one or two sensory nerves were tested. 
Table 1 Electrodiagnostic and clinical profiles

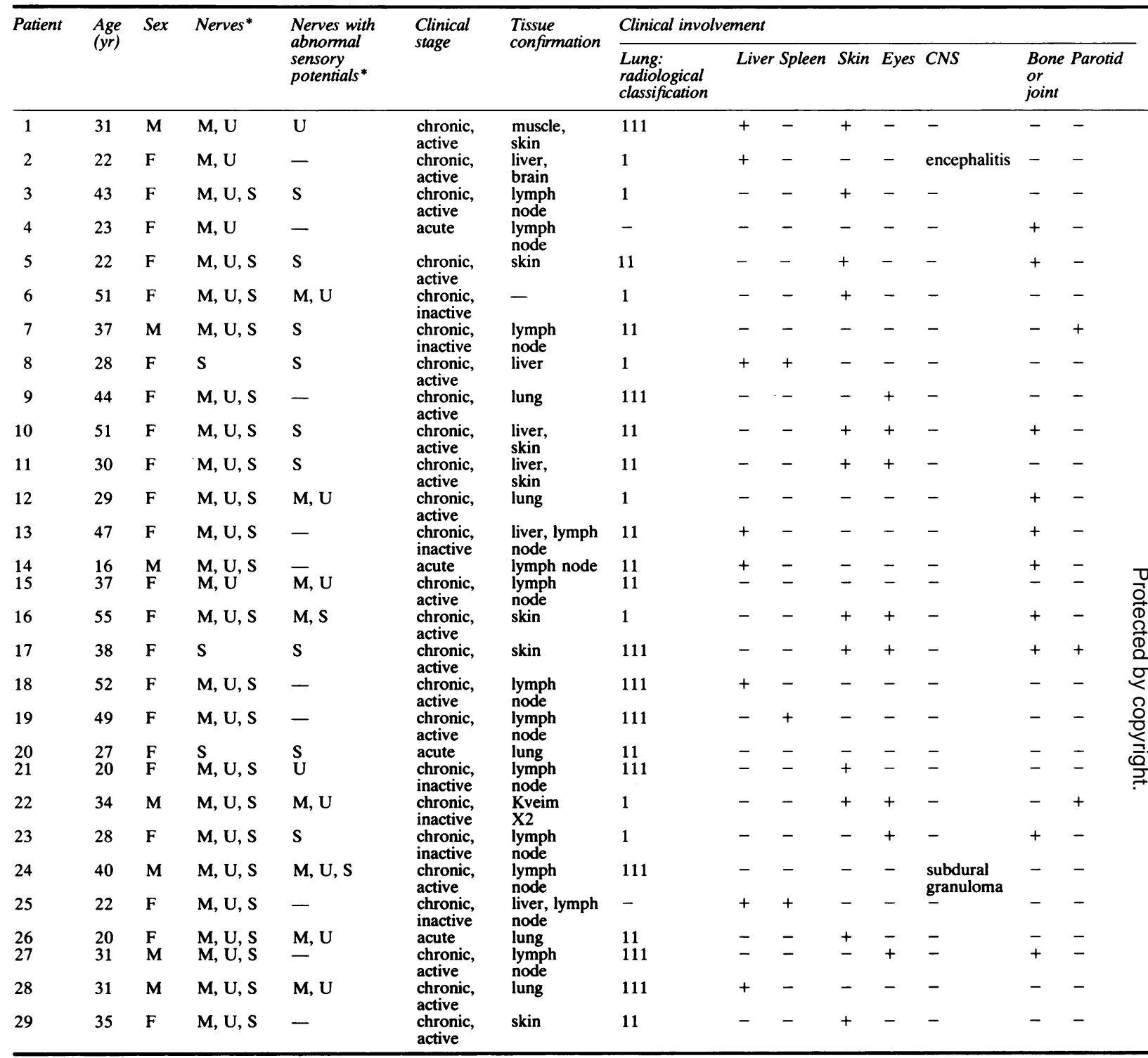

${ }^{*} \mathrm{M}=$ median nerve, $\mathrm{U}=$ ulnar nerve, $\mathrm{S}=$ sural nerve.

Needle electromyography was performed using monopolar electrodes and sampling several distal and proximal limb muscles, initially at rest, in order to evaluate the presence or absence of abnormal spontaneous electrical activity. Motor unit potentials were then observed during voluntary muscle contraction, and note was made of numbers and configuration of motor units.

\section{Results}

There was no EMG evidence of denervation in sarcoidosis patients or in controls; muscles were electrically silent at rest, with normal numbers and configuration of motor units. Motor conduction vel- 
Table 2 Sensory amplitudes in microvolts

\begin{tabular}{|c|c|c|c|c|c|c|}
\hline & \multicolumn{2}{|l|}{ Sural } & \multicolumn{2}{|l|}{ Median } & \multicolumn{2}{|l|}{ Ulnar } \\
\hline & Patient & Control & Patient & Control & Patient & Control \\
\hline 1 & - & - & 50 & 60 & 20 & 50 \\
\hline 2 & - & - & 52 & 60 & 40 & 50 \\
\hline 3 & 10 & 30 & 40 & 30 & 30 & 30 \\
\hline 4 & - & - & 45 & 100 & 35 & 80 \\
\hline 5 & 10 & 40 & 60 & 90 & 46 & 60 \\
\hline 6 & 12 & 26 & 12 & 90 & 13 & 75 \\
\hline 7 & 0 & 25 & 115 & 50 & 45 & 30 \\
\hline 8 & 10 & 12 & - & - & - & - \\
\hline 9 & 12 & 24 & 34 & 75 & 28 & 35 \\
\hline 10 & 7 & 15 & 100 & 25 & 80 & 60 \\
\hline 11 & 10 & 22 & 70 & 90 & 100 & 70 \\
\hline 12 & 30 & 15 & 24 & 100 & 19 & 90 \\
\hline 13 & 28 & 30 & 40 & 92 & 30 & 55 \\
\hline 14 & 24 & 15 & 80 & 75 & 55 & 50 \\
\hline 15 & - & - & 20 & 60 & 26 & 45 \\
\hline 16 & 7 & 15 & 25 & 35 & 50 & 35 \\
\hline 17 & 6 & 25 & - & - & - & - \\
\hline 18 & 20 & 34 & 100 & 55 & 70 & 90 \\
\hline 19 & 14 & 18 & 40 & 80 & 45 & 70 \\
\hline 20 & 10 & 10 & - & - & - & - \\
\hline 21 & 14 & 15 & 38 & 90 & 28 & 80 \\
\hline 22 & 12 & 40 & 25 & 85 & 20 & 65 \\
\hline 23 & 10 & 20 & 65 & 78 & 60 & 75 \\
\hline 24 & 10 & 35 & 16 & 45 & 10 & 50 \\
\hline 25 & 25 & 25 & 32 & 35 & 35 & 50 \\
\hline 26 & 16 & 23 & 20 & 40 & 20 & 50 \\
\hline 27 & 15 & 35 & 36 & 35 & 45 & 60 \\
\hline 28 & 15 & 20 & 16 & 68 & 12 & 72 \\
\hline 29 & 19 & 40 & 50 & 75 & 35 & 100 \\
\hline
\end{tabular}

Table 3 Sensory potential amplitude analysis

\begin{tabular}{|c|c|c|c|c|c|c|c|c|c|c|}
\hline \multirow[t]{2}{*}{ Nerve } & \multirow{2}{*}{$\begin{array}{l}\text { Numbers of } \\
\text { samples* }\end{array}$} & \multicolumn{2}{|c|}{ Mean $(\mu V)$} & \multicolumn{2}{|l|}{$S D$} & \multicolumn{2}{|l|}{$S E M$} & \multirow[t]{2}{*}{$t$} & \multirow[t]{2}{*}{$d f$} & \multirow[t]{2}{*}{$p$} \\
\hline & & Patients & Controls & Patients & Controls & Patients & Controls & & & \\
\hline $\begin{array}{l}\text { Median } \\
\text { Ulnar } \\
\text { Sural }\end{array}$ & $\begin{array}{l}26 \\
26 \\
25\end{array}$ & $\begin{array}{l}46 \\
38 \\
14\end{array}$ & $\begin{array}{l}66 \\
61 \\
25\end{array}$ & $\begin{array}{r}27 \\
22 \\
7\end{array}$ & $\begin{array}{r}23 \\
19 \\
9\end{array}$ & $\begin{array}{l}5.41 \\
4 \cdot 19 \\
1.43\end{array}$ & $\begin{array}{l}4.59 \\
3.70 \\
1.83\end{array}$ & $\begin{array}{l}2 \cdot 77 \\
3.92 \\
4 \cdot 61\end{array}$ & $\begin{array}{l}50 \\
50 \\
48\end{array}$ & $\begin{array}{l}0 \cdot 1 \\
0 \cdot 1 \\
0 \cdot 1\end{array}$ \\
\hline
\end{tabular}

*22 patients and 22 controls had all 3 sensory latencies tested: the remainder had one or two.

$\mathrm{SD}=$ standard deviation, $\mathrm{df}=$ degrees of freedom, SEM = standard error of the mean.

ocities, amplitudes of evoked motor potentials, and sensory distal latencies showed no differences between patients and controls. Nineteen sarcoidosis patients, however, had abnormally low sensory amplitudes in one or more nerves (tables 1 and 2), and the mean sensory amplitudes for median, ulnar, and sural nerves were lower in the patients than in the controls (table 3), two of whom had single borderline low amplitudes.

\section{Discussion}

The frequency in sarcoidosis of peripheral nerve lesions, and whether they represent mononeuropathy multiplex or diffuse peripheral neuropathy, have been difficult to determine. ${ }^{6}$ Most reports of patients with neurological complications did not include electrodiagnostic studies, and a number of authors ${ }^{1}{ }^{10}$ based the diagnosis of sarcoid peripheral nerve involvement on symptoms of paraesthesiae and numbness and signs of muscle atrophy, weakness, and loss of reflexes. Such symptoms and signs, when mild, may be overlooked, and there has been infrequent use of screening electrodiagnostic studies in neurologically normal patients. Moreover, when weakness or sensory loss are present, it is not always clear, without electrical studies, whether the cause is mononeuropathy multiplex, diffuse peripheral neuropathy, or even radiculopathy.

In some instances, symptoms and signs have suggested diffuse peripheral neuropathy, but electrodiagnostic studies have shown otherwise. For example, Par $e a^{4}{ }^{4}$ reported a patient with bilateral leg pain, dysesthesiae, and weakness. Electrodiagnostic studies showed denervation in proximal and 
distal leg muscles, excluding quadriceps, with normal sciatic and peroneal conduction velocities, suggesting lumbosacral radiculopathy. Without electrical studies, this patient might have been considered to have peripheral neuropathy.

Examples in sarcoid of diffuse peripheral neuropathy, with the diagnosis supported by electrical studies, are few. Wells ${ }^{8}$ described two cases of suspected sarcoid "peripheral neuritis". In one, signs resolved with corticosteroid therapy, and nerve conduction velocities were said to return to normal, but the original conduction abnormality was not recorded. In the second case conduction studies were not reported. Of Silverstein's four cases of sarcoid peripheral neuropathy, two with motor and two with mixed sensorimotor findings, one of the latter two had electrophysiological studies, demonstrating slowing of peroneal nerve conduction velocity of unspecified extent, with anterior tibialis denervation. Symptoms and electrical abnormalities improved with corticosteroid therapy during both the first episode of neuropathy and a recurrence six years later. ${ }^{2}$ Two other cases had EMGs showing denervation in resting muscles, without further details offered. One of these had slow nerve conduction velocities, also of unspecified extent. Delaney ${ }^{6}$ mentioned two cases of peripheral neuropathy, one diagnosed by absent ankle jerks alone, and the other on the basis of absent ankle jerks, decreased vibratory sensation at feet and ankles, and slow nerve conduction velocities without specific values.

Sarcoid peripheral neuropathy may simulate Guillain-Barré syndrome in signs and course ${ }^{412}$ and CSF, ${ }^{12}$ but could be a random unrelated occurrence of the two diseases. Sarcoid mononeuropathy multiplex is attributed to infiltration of the nerves by granulomata. The pathogenesis of diffuse neuropathy in sarcoidosis is less certain. Oh, ${ }^{5}$ however, showed sarcoid granulomata in the epineurial and perineurial spaces, with periangiitis and moderate demyelination, in the sural nerve of a patient with symmetrical peripheral neuropathy. Electrophysiologic studies were compatible with axonal neuropathy: mild slowing of motor nerve conduction velocities and distally predominant denervation. Nemni et al ${ }^{13}$ also reported symmetrical peripheral neuropathy with marked slowing of peripheral nerve conduction. Sural nerve showed endoneurial granulomata and local displacement of nerve fibres with loss of larger myelinated fibres.
In our asymptomatic sarcoid patients EMG revealed no denervation. Motor nerve conduction velocities and sensory latencies were normal, but 19 of the 29 patients showed abnormally low amplitude of evoked sensory potentials in one or more nerves, suggesting that subclinical peripheral nerve lesions are common in sarcoidosis. Inasmuch as most of our patients had a mixture of involved and uninvolved nerves we suspect that asymptomatic compression of individual nerves by granulomata (subclinical mononeuropathy multiplex) is the underlying lesion. We found no evidence of diffuse peripheral neuropathy. Sensory nerve dysfunction did not correlate well with clinical severity or duration of sarcoidosis. Correlation of our electrical findings with sural nerve biopsy observations would make an interesting future study, but would be difficult to achieve in an asymptomatic population.

\section{References}

' Wiederholt WC, Siekert RG. Neurological manifestations of sarcoidosis. Neurology (Minneap) 1965; 15: 1147-54.

${ }^{2}$ Silverstein A, Feuer MM, Siltzbach LE. Neurologic sarcoidosis. Arch Neurol 1965;12:1-11.

${ }^{3}$ Matthews WB. Sarcoid Neuropathy. In: Dyck PJ, Thomas PK, Lambert EH, eds. Peripheral Neuropathy. Philadelphia: Saunders, 1975;2:1199206.

${ }^{4}$ Par MM, Schott B, Michel D, et al. Polyradiculoneurites au cours de la maladie Besnier-Boeck-Schaumann. J Med Lyon 1968;49:931-7.

${ }^{s} \mathrm{Oh}$, SJ. Sarcoid polyneuropathy: a histologically proved case. Ann Neurol 1980; 7:178-81.

- Delaney, P. Neurologic manifestations in sarcoidosis. Ann Int Med 1977;87:336-45.

' Colover, J. Sarcoidosis with involvement of the nervous system. Brain 1948;71:451-75.

${ }^{8}$ Wells, CEC. The natural history of neurosarcoidosis. Proc R Soc Med 1967;60:40-43.

${ }^{9}$ Salm R. Familial sarcoidosis terminating as neurosarcoidosis. Post-grad Med J 1969;45:668-74.

${ }^{10}$ Feiling A, Viner G. Irdocyclitis-parotitis-polyneuritis: a new clinical syndrome. J Neurol Psychopathol 1922;2:353-8.

" Rinne UK. Neurologische manifestationen der sarcoidose. Deutsch z Nervenheilk 1967;191:245-56.

${ }_{12}$ Börner E. Löfgren-Syndrom (akuter Morbus Boeck) mit Polyneuritis. Deutsch Med Wschr 1968;93:1956-65.

${ }^{13}$ Nemi R, Galassi G, Cohen M, et al. Clinical and pathologic study of symmetrical sarcoid polyneuropathy. Neurology (Minneap) 1980;30:408. 